\title{
POR UMA POÉTICA DO SINCRETISMO TROPICAL
}

\author{
Léa Freitas Perez*
}

Este texto é o produto de um desejo de olhar diferentemente o Brasil, de ver o país de uma maneira que é, evidentemente, uma interpretação, mas uma interpretação que se pretende aberta e que ambiciona escapar das soluções preguiçosas e ultrapassar a abordagem moderna e nostálgica de que o país tem sido objeto e instaurar em seu lugar um saber alegre e generoso. Trata-se de realizar um exercício de reflexão e uma tomada de posição no que diz respeito às relações da sociedade brasileira com a modernidade e, mais particularmente, de fazer uma crítica a uma certa concepção do Brasil para a qual, em nosso país, a modernidade é um projeto inacabado.

No campo político e intelectual brasileiro, em seus discursos e em seus planos existe, desde o século XIX, uma nota comum: o país seria ainda incompleto, ele deveria se "modernizar" para "conquistar seu lugar no concerto das nações desenvolvidas". O que faria falta ao Brasil seria, então, a modernidade. Sonho e obstinação. Se é a modernidade que faz falta, é preciso, então, se perguntar o que é o moderno, como a modernidade é definida no Brasil. A modernidade é, ao mesmo tempo, um valor em si e o paradigma de desenvolvimento, de estabelecimento da Ordem e do Progresso no país. Ela é, assim, antes de tudo, e acima de tudo, o projeto de construção da "sociedade e da identidade nacionais" que se realizaria pela via da ultrapassagem da situação de atraso e de subdesenvolvimento resultante da recente e ainda viva

* Instituto de Filosofia e Ciências Humanas - PUCRS - Porto Alegre - RS.

Estudos Ibero-Americanos. PUCRS, v. XVIII, n. 2, p. 43-52, dezembro, 1992 
"condição colonial". Ser moderno, e eis aqui uma petição de princípio, é também o modelo de pensamento e de ação através do qual o Brasil deveria atingir a modernidade, isto é, a substituiçâo das estruturas tradicionais (leia-se coloniais). Enquanto projeção para o futuro, a modernidade comporta a realização da "sociedade e da identidade nacionais" vistas como condição de possibilidade de concretizaçâo da modernidade ela mesma. O Brasil seria, nos dizem, "sem identidade" porque o tradicional que conhecemos - o colonial - é "mau" e que o moderno que temos é apenas parcial - um "falso moderno" - nâo completamente desenvolvido no conjunto da sociedade. Esta maneira de conceber o Brasil e de agir sobre sua realidade é dominante num segmento bastante expressivo da sociedade. Ela agrupa pessoas de formações diversas, num espectro que vai da esquerda mais radical à direita mais selvagem, e constitui, desde do século XIX, o "fundo de comércio" da maior parte dos políticos e intelectuais do país.

Esta concepçâo se articula em torno de uma "lógica da falta", operando a partir de oposições binárias, sobretudo com as oposições tradicional-moderno e centroperiferia. A doxa corrente costuma apresentá-la sob a etiqueta dos "dilemas brasileiros". Assim, o Brasil seria "o país do futuro", ele teria imensas potencialidades, mas, no presente, essas potencialidades encontrar-se-iam bloqueadas em seu florescimento devido à "falta de modernidade". Dito de outro modo: o país seria ainda uma potencialidade - "o gigante adormecido" e não uma realidade acabada. As condições de acesso à modernidade estariam limitadas pelo subdesenvolvimento econômico e pelas disparidades sociais que dividiriam o país em dois. Um "país dual" formado por contrastes e por contradições. O norte, agrário, subdesenvolvido, pré-capitalista, tradicional e atrasado. $\mathrm{O}$ sul, industrial, urbano, rico, moderno e avançado. As favelas e os arranha-céus. A cidade e o campo e assim sucessivamente. Os "dois Brasis", eterna e irremediavelmente divorciados, de costas um para o outro. Uma "terra de contras. tes" formada por uma sociedade dividida em duas grandes metades em perpétuo conflito e oposição. Uma "sociedade a duas velocidades", cindida entre o moderno e o tradicional, entre a ordem e a desordem. O primeiro Brasil seria um fardo um fardo para o segundo. O "mau" Brasil seria uma herança dos "tempos coloniais", enquanto que o "bom" país seria uma "conquista das forças de Ordem e de Progresso que, depois da independência, lutariam, sem parar, pela independência e pela integração nacionais". Um exemplo característico deste tipo de diagnóstico da situação atual do país é dado pelas observações de Caio Prado Júnior. Segundo este autor, o passado colonial "ainda nos cerca de todos os lados", ele "ainda está, e bem saliente; em parte modificado, é certo, mas presente em traços que nâo se deixam iludir". Ele diz ainda que "observando-se o Brasil de hoje, o que salta à vista é um organismo em franca e 
ativa transformação e que não se sedimentou ainda em linhas definidas; que não "tomou forma" porque "não completamos ainda hoje a nossa evolução da economia colonial para a nacional"1.

Ora, não há a menor dúvida de que a modernidade, enquanto projeto que se pretende "civilizador", se estabelece contra a tradição, isto é, contra tudo que precede. Vale dizer que ela age como um vetor, isto é, que ela tem uma orientação e um sentido que se encaminham parar a realização última e final da Razâo e do Progresso, de uma nova ordem, a da produtividade, do desenvolvimento racional dos meios de produção, de sua gestâo e de sua organização numa perspectiva de eficácia e de rendimento máximo, onde o indivíduo - livre e autônomo - é o mestre e senhor de seu destino, etc. A modernidade, vetor da ruptura com a tradição, "o tempo findo", se quer "sempre "contemporânea", ou seja, simultaneidade mundial"2. Ela é assim universalista e homogeneizante.

Na América Latina, esses valores e princípios do pensamento moderno são traduzidos através das teorias da modernização e da dependência. Estas teorias são, desde a Segunda Guerra Mundial, os apoios ideológicos e os modelos explicativos da modernidade na América Latina. O subdesenvolvimento é sinônimo de marginalidade sócio-econômica. A marginalidade está em relação com a dependência vis-à-vis dos centros do capitalismo mundial. Existe, portanto, uma clara visão da existência de um centro, que é a vanguarda onde tudo é criado - de forma original - e que, nessa medida, tudo comanda, e de uma periferia, que não passa de uma retaguarda, onde tudo é cópia e, em sendo cópia, é sem originalidade. As sociedades do Terceiro Mundo seriam subdesenvolvidas, pois elas não teriam conhecido, por causa do "colonialismo", um desenvolvimento igual aos das nações européias. A modernização, enquanto sinônimo de crescimento econômico segundo os padrões europeus, seria o único meio e o único caminho para sair da marginalidade e da dependência. Modernização equivale assim a mudança e desenvolvimento, numa ótica claramente evolucionista - os mesmos processos levariam ao mesmo fim - segundo um modelo linear e dicotômico, onde o tradicional e o moderno seriam os dois pólos, opostos de um mesmo continuum. O tradicional, isto é, a realidade conhecida desde sempre, é o pólo do subdesenvolvimento, da marginalidade, da pobreza, da dependência. O moderno, o fim desejado, é o pólo da industrialização e da urbanização, de taxas elevadas de educação e de mobilidade social, de independência nacional sob a forma de Estadonação, etc. O ponto focal da mudança seria a industrialização, estritamente associada ao desenvolvimento sócio-econômico, que, bem implantado, agiria no conjunto da sociedade subdesenvolvida de maneira a aproximá-la das sociedades desenvolvidas. A industrialização é tomada, portanto, como o fator por excelência da homogeneização 
das diferenças, segundo uma visão messiânica do poder da economia para resolver todos os problemas e uma concepção estreita da Civilizaçâo, do Progresso enquanto fatores de base do Desenvolvimento. Essas teorias revelam que, nos países ditos subdesenvolvidos, o dito Terceiro-Mundo, a modernidade é pensada primeiro em seus aspectos técnicos. Nessa visâo está implícita a aceitação de que "o conjunto das sociedades globais, para melhorar, deve tomar o caminho da monotonia"3.

Aplicadas ao Brasil, essas teorias conformam uma visão segundo a qual a persistência da tradição é, ao mesmo tempo, um sintoma e uma prova da execução apenas parcial do projeto moderno. Ora, como a tradição que temos - independente de nossos desejos - é a da colonizaçâo portuguesa, é a ela que se deve atacar. O raciocínio implícito é o seguinte: é preciso destruir completamente esse passado colonial que é uma mancha e um entrave à Ordem e ao Progresso e, em seu lugar, construir um país e uma sociedade autenticamente "nacionais" e "uma nova ordem em sintonia com o mundo contemporâneo". Em nome da modernidade, revoluções são feitas, golpes de estado são deflagrados, cidades inteiras são remodeladas, novas cidades são criadas, a história é re-escrita, um tipo autenticamente nacional é procurado, etc. Uma série de interminável de operações é posta em marcha com o objetivo de pôr em seu verdadeiro e legítimo lugar as coisas e os homens, segundo um princípio de que o Brasil é um "país exportador de matérias-primas e importador de idéias", sofrendo, ao mesmo tempo, do atraso econômico e do mimetismo ideológico, ambos compondo um abismo entre a "realidade real" do país - o subdesenvolvimento econômico - e sua "fachada ideológica" - o liberalismo. Em nome da modernidade redentora, se coloca o calendário histórico num ponto zero a partir do qual tudo deveria ser re-feito. Mas como não temos todo o tempo do mundo, é preciso fazer rápido, saltar as etapas, ir o mais rápido possivel para recuperar o tempo perdido. O slogan dos anos 1950-1960, "fazer progredir o Brasil cinqüenta anos em cinco" é ilustrativo da visão desenvolvimentista dominante.

De fato, o que existe nesta concepção do Brasil e de seus dilemas de país dividido é uma forma de "tradicionalização do moderno". Segundo a formulação de Gabriel Cohn, "a modernidade é, simultaneamente, projeto à nossa frente, utopia jamais realizável plenamente, e tradição às nossas costas, ideologia do ajuste tendencial ao presente sob o peso do passado" 4 . Vivemos uma sorte de nostalgia do que jamais existiu, segundo um raciocínio do tipo "se tivesse sido diferente". Ah, se o Brasil tivesse sido colonizado pelos ingleses, tal como os Estados Unidos! Ah, se os holandeses ou os franceses não tivessem sido expulsos! O Brasil seria hoje uma grande potência! Resumindo: a colonizaçâo portuguesa é a causa de todos os problemas - os ditos males e paradoxos do país. 
A modernidade, enquanto campo intelectual é, no Brasil, essencialmente passeísta, visceralmente apegada a um passado idealizado que jamais existiu e fundada sobre uma crença messiânica nos poderes redentores da modernidade. Vejamos alguns exemplos. A grande questão, para os intelectuais brasileiros do século XIX, era a re-escritura da história do país, tomando-a como sendo a condição mesma da plena realização e da afirmação política do projeto nacional, a partir de uma visão do nacional como desdobramento do geral, da Civilização e do Progresso. Neste contexto é criado, em 1838, o Instituto Histórico Geográfico, tendo por tarefa a escritura da História Geral do Brasil, visando, através dela, definir os contornos da nação em gestaçâo, integrando-a ao "Mundo Civilizado", ou seja, a Europa. Este mesmo tipo de preocupaçâo é re-atualizado durante os anos 1950-1960, época em que a questão central era a de uma "luta pela autonomia nacional sob o plano econômico", dito de outro modo, de ultrapassar o subdesenvolvimento. Nesta conjuntura, é criado o Instituto Superior de Estudos Brasileiros, que não era outra coisa senâo uma versão contemporaneizada do IHG. A produção do ISEB articulava-se em torno de conceitos tais como "alienação" e "situação colonial" e seu objetivo era determinar as medidas necessárias para "a ultrapassagem da dominação colonial". O tempo passa e as preocupações parecem continuar sempre as mesmas, como se o tempo não tivesse efetivamente agido e o país não tivesse mudado. Neste tipo de raciocínio, a afirmação de Caio Prado Júnior é exemplar. Segundo ele, "a evolução brasileira de simples colônia tropical à nação" é um processo "difícil e doloroso", ainda não completa5. Esta mesma linha é seguida por Roland Corbusier, um dos papas da modernização, que dizia, nos anos 1960, que o Brasil era um país que não tinha passado e que, em consequiência, não podia ser senão futuro: "Somos o invólucro vazio de um conteúdo que não é nosso porque alheio. Enquanto colônia, não temos forma própria porque não temos destino"6. Para Florestan Fernandes, um dos mais respeitados analistas do Brasil, nas sociedades dependentes e de origem colonial, o capitalismo foi introduzido antes da ordem social da competição. Vale dizer que a burguesia brasileira, enquanto portadora do espírito de modernização, teria implantado uma democracia restrita e teria utilizado as transformações capitalistas para o reforço de seus interesses de grupo $^{7}$. Numa outra linha de pensamento, mas fiel à lógica da falta, Roberto Schwarz caracteriza a situação do liberalismo brasileiro do século XIX como estando "fora de lugar", porque haveria um hiato entre a intenção e a realização do projeto liberal num país ainda submetido à ordem escravagista ${ }^{8}$. Ora, este tipo de raciocínio paradigmático do mito da modernidade inacabada, parece forçar a mão e ignorar a realidade histórica. O que é a competição senão um dos instrumentos a partir dos quais se estabeleceu a ordem da monopolização, ela mesma nâo sendo outra coisa que a 
socialização do monopólio privado de alguns indivíduos isolados que se torna o monopólio de camadas sociais mais amplas? Como diz Norbert Elias, neste processo é questão da passagem do monopólio privado para o monopólio público\%. Quem pode afirmar que a democracia é incompativel com o monopólio, ou que o escravismo moderno não obedece a uma lógica de mercado? Do mesmo modo, quer na construção da dita "cultura nacional", quer na "modernização" do país, se tratou muito mais de uma extensâo e de um aprofundamento das relações com a Europa e com os Estados Unidos do que de uma efetiva ultrapassagem da "condição colonial" e da "herança portuguesa".

Jean Braudrillard resumiu, de maneira exemplar, o que eu gostaria de dizer sobre a modernidade nos trópicos. Diz ele que a modernidade é "movente em suas formas, em seus conteúdos, no tempo e no espaço, ela não é estável e irreversível senão como sistema de valores, como mito". Assim entendida, a modernidade "se assemelha à Tradição". Diz ainda Braudrillard que a modernidade "não é jamais mudança radical ou revolução", ao contrário, ela "sempre entra em implicação com a tradição num jogo cultural sutil, num processo de amálgama e de adaptação"10. É exatamente isso a tradicionalização do moderno no Brasil. O problema é que a doxa cria uma confusâo entre reformismo, desenvolvimento sócio-econômico e modernidade, de maneira que, ao fim, tanto a tradição, como a modernidade são retificadas e seus respectivos conteúdos acabam deformados.

Quando o Brasil se coloca a questâo da modernidade, ele o faz não por causa de uma falta de modernidade, justamente ao contrário, ele se coloca a questâo por causa de uma crise de modernidade, de uma percepção dos limites de realização do projeto moderno. O mito da modernidade inacabada é, antes de tudo, uma prova de que no país as idéias estavam em seu lugar, que o príncipe da crise enquanto valor moderno já existia. Desde o fim do século XVII se fala em crise no Brasil e na necessidade de modernização, isto é, de reformas. Esta discussão, que adquire a partir dos anos 1850 o foro de questâo central em toda e qualquer abordagem sobre o Brasil, é contemporânea da apariçâo da palavra modernidade, que data do mesmo período. É exatamente nesta época que a sociedade moderna se pensa a si mesma enquanto tal.

A modernidade brasileira é plena de oxímoros, isto é, toda ela feita de contrastes violentos, de transformações bruscas, de reviravoltas, de altos e baixos, de aproximações imprevistas de todas as ordens. É preciso abandonar as idéias equivocadas e aceitar que a colonização portuguesa operou a partir do espírito da época, isto é, do projeto moderno, todavia, entre o projeto e sua aplicação há a criação de uma realidade particular, o Brasil. Se a modernidade é a tradição de base da nossa configu- 
ração histórica, ela foi - desde o começo - combinada a outros componentes e o resultado é a constituição de uma sociedade que combina várias racionalidades, códigos e modos de organização. Para compreender a realidade brasileira não é possível que nos contentemos com noções ad hoc tais como "país do futuro", "sociedade dual", etc. No lugar das questões que procuram explicar porque no Brasil a modernidade é um projeto inacabado e porque é persistente a presença da tradição, proponho mudar o registro e ver como, na formação histórico-social do Brasil, existe desde o começo - um princípio de organização que é a da ordem do sincretismo e do qual resultou a formação de uma realidade mestiça, de hibridização de códigos e de modos de ser. Na constituição e no desenvolvimento da sociedade brasileira ocorreram mudanças e continuidades que fazem parte não de uma persistência de uma tradiçâo colonial, como, por exemplo, o patriarcalismo e o patrimonialismo, mas de um modo singular de organização, a mestiçagem ${ }^{11}$. O problema que se coloca, e ele se coloca para os românticos da modernidade redentora, é que, no movimento histórico brasileiro, não houve a ruptura mítica que a modernidade supõe. Aqui, uma dinâmica da mestiçagem tomou o lugar da dialética da ruptura.

O Brasil se organizou socialmente não a partir de uma lógica de exclusão e de contradiçào, mas segundo uma lógica da relatividade e da inclusão, que não exclui 0 conflito, mas o incorpora como um dado de base. Uma forma de harmonia conflitual, da qual a cidade é um dos melhores exemplos. O resultado é uma sociedade, que combina contrastes e antagonismos os mais variados, irredutivel a uma abordagem rígida. A heterogeneidade de nossa organização social se dá no plano e uma rede de relações múltiplas. Com seu sistema híbrido de composição, feito de complementariedades e de conflitos, o Brasil é um problema para a lógica cartesiana. Na nossa lógica social, o princípio em vigor não é o tipo ou... ou, ao contrário, trata-se, todo o tempo, de reunir, de re-ligar. É um princípio de tipo e... e. A sociedade brasileira, como o pensamento religioso, segundo a formulação durkheimiana, tem "um gosto natural tanto pelas confusões intemperantes, quanto pelos contrastes agudos". O pensamento religioso é "voluntariamente excessivo nos dois sentidos", ele utiliza "os mecanismos lógicos com uma sorte de gaucherie, sem portanto ser ilógico"12. Como não apreciar, de modo mais generoso, o caráter híbrido, compósito, sincrético, mestiço da sociedade brasileira, essencialmente avessa, irredutível a uma decomposição ordenada, linear de seus elementos constitutivos, depois desta maravilha de análise sociológica? O princípio de organização social que prevalece em nossa sociedade, queiramos ou não admiti-lo, é o da plasticidade e do movimento. E plasticidade e movimento são traduzidos, no Brasil, através da festa. 
No passado, como hoje, a festa é o espaço por excelência de reunião social, de assembléia coletiva e de socialidade. Na festa à brasileira o que importa, acima de tudo, é a ação, a participação ativa. O que vale e prevalece é a assembléia efervescente, a exaltação geral, o carnavalesco próprio à festa, $\mathrm{O}$ carnaval e as festas religiosas, formas de espetáculo por excelência, dizem respeito a uma maneira particular de viver a sociedade e de perceber o mundo. No Brasil, o carnaval é mais que uma festa, ele corresponde a um modo de ser e de viver, a um princípio de organização social que caracteriza o mais profundo deste pais. Entre nós, tudo começa e tudo termina pelo carnaval, o que vale dizer que nada começa verdadeiramente, tanto quanto nada tem fim. Nós vivemos sempre em trânsito, em movimento, na abundância carnavalesca. Neste modo de viver, a realidade não é negada, exatamente o contrário, ela é transfigurada e exacerbada por um realismo irônico que, em a afirmando, ri dela.

As relaçōes sociais no Brasil sẫo marcadas pelo afetivo, que, não importa qual seja sua manifestação, é levado a extremos: a sensualidade altamente desenvolvida, o exotismo do gosto, o exagero dos gestos e das falas, a religiosidade carnal, profana, a aversão às distâncias rígidas, o apelo constante à intimidade, etc. Uma sociedade sinuosa mesmo na violência, onde a complacência é sempre presente. Um organismo social de abundância e de generosidade, de seduçâo, o que, no entanto, não quer dizer igualdade e harmonia idílicas. Parcimônia e cálculo são estrangeiros ao modo de ser brasileiro. A sinuosidade das costas maritimas, as linhas serpentinas dos belos corpos bronzeados, desnudos, o perpétuo espetáculo da vida exposta permanentemente, quer no quotidiano, quer nas festas. Uma sociedade alegre mesmo na tragédia. Toda feita de curvas, de viravoltas em todos os sentidos, jamais linear, jamais igual a si mesma. Penso em coisas tipicamente brasileiras: o prazer de furar a fila, alegremente, sorriso nos lábios, sinuoso; aproximar-se de um desconhecido como se ele fosse um velho amigo, o tapinha no ombro num convite à proximidade e à intimidade; 0 "aparece lá em casa", dito em qualquer ocasião, etc. Uma moleza e uma doçura sensuais nos contatos humanos que, ao mesmo tempo, reforçam e dissimulam quer as diferenças, quer as semelhanças. Nós estamos sempre lado a lado uns dos outros, sem estarmos efetivamente juntos. Uma certa perversidade nas relações.

É exatamente isso o exotismo tropical: a carnavalização e a mestiçagem en. quanto princípio de organização social. Não é um simples coincidência se definimos o Brasil e sua lógica social através do carnaval, o espaço por excelência do sincretismo e das trocas múltiplas, onde o princípio de identidade e de contradição são postos em causa. Da combinação entre as relações pessoais levadas ao extremo (espaço de negociações e de alianças as mais variadas), a religiosidade carnal e complacente, a concepção carnavalesca do mundo, da vida pensada como uma festa, resulta um 
sistema social mestiço, marcado pela fluidez, onde a noção de falta faz falta, onde o entrecruzamento dos extremos é a regra. A sociedade brasileira nâo pode ser apreciada sem que se leve em consideração seu incessante movimento, sua incompatibilida. de com soluções definitivas, sua composição mole, plástica, ondulante, sua estrutura sincrética e carnavalesca. Nós não podemos e não queremos separar as coisas, interdiçôes rígidas não tem lugar, nem vez.

A realidade brasileira, plástica em sua composição e movente em seu funcionamento, não pode ser analisada através de conceitos rígidos. Como percebeu a fina sensibilidade de Roger Bastide, " o sociólogo que estuda o Brasil não sabe que sistema de conceitos utilizar". Para penetrar nesta realidade, é preciso "descobrir noções que sejam, de algum modo, líquidas, capazes de descrever os fenômenos de fusão, de ebulição, de interpenetração, que se moldariam sobre uma realidade viva, em perpétua transformação" 13. Diante deste país complexo e intrincado, e para ser generoso, não existe senão uma via de compreensão: se moldar em poeta, como diz com justeza Roger Bastidelí Paremos de procurar a "Revolução" que não existe, a "Grande Transformaçâo" que não tem sentido! Não tombemos na armadilha dos "utópicos nostálgicos dilacerados pelo ideal, mas no fundo repugnando sua realização" 15 . Prestemos mais atenção ao ditado "não existe pecado do lado de baixo do Equador".

\section{NOTAS DE REFERÊNCIA}

1 - PRADO JUNIOR, Caio. Formação do Brasil contemporâneo. Colónia. 1969. São Paulo. Brasiliense, 9. ed (primeira edição 1942). p. 10, 11, 13.

2 - BRAUdrillard, Jean. "Modernité". 1982. In: Biennale de Paris. La modernité ou l'esprit du temps, Paris, Editions L'Equerre, pp. 28-31. p. 29.

3 - QUEIROZ, Maria Isaura Pereira de. "Singularidades sócio-culturais do desenvolvimento brasiIeiro", 1975. In: Revista do Instituto de Estudos Brasileiros n. 16. São Paulo, USP. pp. 63-81. p. 64 .

4 - Gabriel Cohn. Apresentação. ORTIZ, Renato. A moderna tradição brasileira. Cultura brasi. leira e Indústria cultural. 1988. São Paulo, Brasiliense.

5 - PRADO JÚNIOR, Caio. História econômica do Brasil. 1987. São Paulo, Brasiliense, 35 ed. (primeira ediçîo 1945) p. p. 74.

6 - Apud. SANTOS, Afonso Celso Marques dos. "A invenção do Brasil: um problema nacional". 1985. In: Revista de Historia n. 118, janeiro/junho. São Paulo, USP. pp 3-12. p. 8.

7 - Cf. ORTIZ A moderna tradição brasileira. Op. cit. p. 17.

8 - SCHWARZ, Roberto. Ao vencedor as batatas. Forma literária e processo social nos inícios do romance brasileira. 1981. Sào Paulo, Duas Cidades, 2. ed. p. 13.

9 - ELIAS. Norbert La dynamique de lOccident. 1975. Paris, Calmann-Lévy. (traduzido do alemào por Pierre Kamnitzer). p. 35, 39, 40. 
10 - BaUdRILlaRD. "Modernité", Op. cit. p. 28, 30.

11 - Não ignoro que as expressões sincretismo e mestiçagem são problemáticas por causa de certas aplicações ligeiras de que elas foram objeto. Para mim, não se trata de uma simples mistura desordenada e indiferenciada de elementos heteróclitos. Elas expri. mem um modo de operar que é da ordem da simultaneidade, como num jogo de cartas, onde podemos misturar as cartas formando múltiplas combinaçòes, jamais idênticas, sem portanto fundi-las em um todo indistinto. As cartas permanecem cartas. Aquele que tem o poder e que realiza as escolhas, que diga-se de passagem são escolhas que, além das regras formais do jogo, levam em consideraçào dimensôes estéticas e lúdicas, é o jogador.

12 - DURKHEIM, Emile. Les formes élémentaires de la vie religieuse. Le système totémique en Australie 1985. Paris, PUF, ème édition, coll. Quadrige. p. 17, 18, 341, 342.

13 - BASTIDE, Roger. Brésil. Terre des contrastes. 1957. Paris, Hachette. p. $15,16$.

14 - BASTIDE. Brésil. Terre des contrastes. Op. cit. p. 16.

15 - BAUDRILLARD, Jean. Amérique. 1986. Grasset. p. 156. 